\title{
A Corpus-Based Study On Grammar Errors Made By Adult Learners In Sri Lanka
}

\author{
Jasmine Jayasekara \\ Department of English, Advanced Technological Institute, Anuradhapura \\ DOI: 10.29322/IJSRP.11.07.2021.p11531 \\ http://dx.doi.org/10.29322/IJSRP.11.07.2021.p11531
}

\begin{abstract}
This study investigated into the grammar errors made by seventy students chosen from both first and second year classes of Higher National Diploma in English (HNDE) at Advanced Technological Institute (ATI), Anuradhapura in Sri Lanka. An essay written by each participant on a personalized topic was taken into account in identifying their grammar errors. The errors were categorized under three processes: omission, addition and substitution. Later, their errors were analyzed and the sources of these errors were discussed with emphasis on intralingual and interlingual errors. The findings indicate that omission is the process that recorded the highest number of errors, and both groups (first year and second year) have made similar errors.
\end{abstract}

Index Terms- addition, errors, interlingual, intralingual, omission, substitution

\section{INTRODUCTION}

$\mathrm{I}^{\mathrm{n}}$ ne present study, the researcher investigated into second language (L2) writing errors of seventy essays written by students who are currently following Higher National Diploma in English (HNDE) at the Advanced Technological Institute (ATI), Anuradhapura in Sri Lanka.

Anuradhapura is the capital city of the North Central Province (NCP) in Sri Lanka, and it is considered a remote area in Sri Lanka. Thus, the schools of the district lack enough resources to educate the students. Even though the government take measures, still there are schools that have no teachers to teach English. In Sri Lankan schools, English is taught from grade 3 to Advanced Level (A/L) classes. It is taught as a compulsory major at each level: primary, secondary and tertiary level. Therefore, when a student finishes $\mathrm{A} / \mathrm{L}$ examination, he/she has already received ten years of English language education.

The participants of the present study have already finished their A/L with at least a credit pass (C) for English at the Ordinary Level $(\mathrm{O} / \mathrm{L})$ examination. However, these learners still make many grammar mistakes in their L2 writing.

HNDE is a two-year teacher qualification course that provides skills and knowledge for students to become English language teachers at the successful completion of the course. Even though the entire program consists of more than ten modules, a significant improvement cannot be noticed in the students. Except for a few students, the others seem to repeat the errors they used to make at the beginning. This reason inspired the researcher to start a comparative study between $1^{\text {st }}$ year and $2^{\text {nd }}$ year students' L2 writing production. Also, the researcher intended to find out sources of these errors. Writing skill is the major focus of this study since the course content of HNDE program places much emphasis on writing essays.

This research is based on four main research questions that focus on the first year and second year students' writing errors:

Do the errors made by the first and second year students differ? If they do, to what extent? What frequencies are there? What types are there?

Also, this study is based on four objectives:

- To identify the writing errors made by first year and the second year students

- To compare and contrast their writing errors

- To observe the improvements of their writing productions

- $\quad$ To find out reasons for their errors

\section{REVIEW OF LITERATURE}

In learning a second language (L2), errors that learners make are divided into two categories by [1] Corder (1974: 259 cited in Jabeen 2015). Errors are the result of incomplete learning and linguistic incompetency of the learners and errors cannot be selfcorrected. Mistakes are the results of poor performance of language due to many factors like fatigue and carelessness on the part of learners etc.( Corder 1974, p.259 cited in Jabeen 2015, p.53) An error, by its nature, sounds negative, but the researchers did not consider errors unimportant. They frequently made numerous efforts to identify errors and analyse them in order to discover remedies for these learner errors. Thus, they introduced several theories that dealt with L2 learner errors. Contrastive Analysis (CA) and Error analysis (EA) are the two main theories that described L2 learner errors. Interlanguage (IL) is the most recent theory that was developed from contrastive analysis (CA) and error analysis (EA) to describe learner errors. At first, the influence of the first language (L1) in Second language (L2) learning was considered the cause of L2 learner errors. Later, it was found out that L1 was not the only cause of L2 learner errors, and thus IL came into play.

According to the researchers of late 1960s and early 1970s, the language of a L2 learners is systematic and the errors that they 
make indicate a behavior that is rule governed ( [2] Corder 1976; [3] Selinker 1972). CA was first used to describe this rulegoverned behavior of L2 learners. According to [4] Fisiak (1981,p.1), CA is "a sub-discipline of Linguistics concerned with the comparison of two or more languages or subsystems of language in order to determine both differences and similarities between them". CA was often questioned and criticized based on the fact that interlinguagl interference from L1 is not the only reason for the errors made by L2 learners. Also, it was argued that CA is specialized in phonological level and least specialized in syntactic level [5] (Al-khresheh 2015).

EA emerged in sixties as a reaction to CA that considered L1 as the main source of errors made by L2 learners. It was established by Corder and his colleagues. [6] James (1998, p.11) indicates that "by the late 1960s EA had become the acceptable alternative to the Behaviorist CA of the 1950s." EA also agrees with the Universal Grammar (UG) theory which explains that the rules that we internalize in the cause of L1 acquisition are universal and this reality makes us realize the distance between L1 and L2 and the problems faced by L2 learners ( [7] Comrie 1990 and [8] Major and Faudree, 1996). EA, in fact, placed emphasis on the fact that errors made by learners are not only due to L1 interference but also due to some universal strategies. EA, according to [9] Corder (1967) involves collecting samples of learner language by both teachers and researchers, identifying errors in the sample, describing these errors, classifying them based on their nature and causes, and evaluating their seriousness. Moreover, [10] Khansir (2012 citing Richards 1971, p.1.) stated that error analysis can be defined as "dealing with the differences between the way people learning a language speak and the way adult native speakers of the language use the language".

[11] Sawalmeh (2013 citing Corder 1967) indicates that EA has two objects: theoretical object and applied object. 'The theoretical object is to understand what and how a learner learns when he studies a second language (L2). The applied object is to enable the learner to learn more efficiently by using the knowledge of his dialect for pedagogical purposes'[11] ( Sawalmeh 2013, p.3). Later, [12] Corder (1974, p.170) explain that the purpose of error analysis is to find out " what the learner knows and does not know" and to "ultimately enable the teacher to supply him not just with the information that his hypothesis is wrong, but also, importantly, with the right sort of information or data for him to form a more adequate concept of a rule in the target language.

The empirical study carried by Jabeen (2015) discusses the 'role of error analysis in teaching and learning of second and foreign language'. The data of this study was collected in the form of answer copies of the examinations of the students in the University Of Gujrat and the Unique Language Centre (ULC) in Tabriz, Iran. The data was collected from the students of many departments of the university and various classes in ULC. The participants of both institutes are learning English in order to improve their communicative skills. 150 answer copies were used in this study. Errors were identified in these answer copies and they were divided into four categories: addition, omission, selection and ordering. The analysis was done based on two questions. One is based on precis writing and the other one is based on the translation in which the participants were asked to translate a passage of either Persian or Urdu into English.The analysis of this study was done based on the four categories introduced by Corder (1974 cited in Jabeen2015): addition, omission, selection and ordering. The influence of SMS language was also taken into consideration. According to the data, the participants made more errors in the selection category. As the researcher mentions in the analysis section, the errors made by the learners in terms of the incorrect forms of the verbs according to the tense, and errors made in terms of subject-verb agreement were significant in this study. However, the researcher does not seem to analyze these areas with enough examples in order to highlight theses errors. Apart from these main areas, spelling mistakes, the wrong use of the different parts of speech were also found out.

People plays a very important role in the progress of any country. (Jabeen, 2015, p.59)

This sentence is an example sentence to highlight the process of addition in which the learner uses the morpheme's' additionally. It is pointed out that the reason can be overgeneralization of an existing rule or insufficient knowledge of this rule of the L2.

Writer has writing this story from two years. (Jabeen, 2015, p.59)

Here, the error type is omission as the learner omitted the past participle form of the 'be' verb that is 'been' in between 'has' and 'writing'. This error is caused by the learner's lack of knowledge to use the correct forms of the verbs according to the tense. Also, in this example sentence, the researcher tries to highlight an error that is caused by the negative transfer and the interference of the mother tongue. That is where the learner substitutes the incorrect preposition 'from' for the correct preposition 'for'.

Another area highlighted by Jabeen (2015) is arranging the words in a correct order. By depicting these errors, the researcher tries to emphasize the learners' inadequate knowledge regarding the rules of the target language.

About this incident unluckily no one is aware. (Jabeen, 2015, p.59)

This is a very good example given by the researcher to indicate the errors made by the L2 learners in terms of placing the words of a sentence in an incorrect order. For example the learner in this instance does not place the subject and verb of the sentence in the first and second position respectively. This incorrect order according to Jabeen (2015) is due to their incompetency of the language.

As the findings of this study suggest, it is important for L2 learners making mistakes in learning a second language and also systematic analysis of errors is also crucial. Moreover, the 
findings emphasize the importance of the error analysis in providing a deep insight into L2 learning.

\section{Sources of Errors}

Two main sources of errors can be identified in the field of applied linguistics: interference of the L1 and intralingual and developmental factors.

\section{L1 influence}

Even though the recent studies place emphasis on intralingual and developmental errors, the influence of L1 in the acquisition of L2 rules is very significant. According to [13] Dulay et al (1982 cited in Bhela 1999, p. 22), interference is 'the automatic transfer, due to habit, of the surface structure of the first language onto the surface of the target language'. Researchers have shown that the L2 writers use L1 elements in their writings. [14] Ellis (1997, p.51) calls interference 'transfer', and according to him, it is 'the influence that the learner's L1 exerts over the acquisition of an L2'. As [15] Mahmoud (2000) shows, learners use L1 transfer as a means of conveying their meaning and to test the hypothesis they formulate regarding L2. Another view is that learners use this to facilitate their L2 writing process as a strategy to make up the deficiencies in their L2 writing [16] (Karim \& Nassaji, 2013).

According to [17] Allen and Corder (1974 cited in Pratiwi 2016, p.4 ), Interlingual errors caused transfer error. Touchie (1986 cited in Pratiwi 2016, p.4) suggested that interlingual errors were caused mainly by mother tongue interference while Al- Khresheh (2010 cited in Pratiwi 2016, p.4) suggested that interlingual errors were caused by literal translation.

1. Transfer Error: error caused by interference from mother tongue. A student who has not known the rules of target language will use the same rules as he obtained in his native language.

2. Mother tongue Interference: errors are produced in the learners' attempt to discover the structure of the target language rather than transferring models of their first language.

3. Literal Translation: errors happen because a student translates his first language sentence or idiomatic expression in to the target language word by word. (Pratiwi 2016, p.4)

\section{Intralingual and development factors}

Intralinguagl and developmental errors occur due to the difficulty of the L2. At first, this source of errors was explained as two kinds: Intralingual errors and developmental errors. Later, both of these categories were merged as one kind since they were found closely related and confusing to differentiate from each other [18] (Schacheter and Celce-Murcia, 1977).

According to [19] Touchie (1986, pp.78-79) intralingual and development errors include following categories.
1) Simplification: Learners often choose simple forms and constructions instead of more complex ones. An example of simplification might involve the use of simple present instead of the present perfect continuous.

2) Overgeneralization: This is the use of one form or construction in one context and extending its application to other contexts where it should not apply.

3) Hypercorrection: Sometimes the zealous efforts of teachers in correcting their students' errors induce the students to make errors in otherwise correct forms.

4) Faulty teaching: Sometimes it happens that learners' errors are teacher-induced ones, i.e., caused by the teacher, teaching materials, or the order of presentation. This factor is closely related to hypercorrection above. Also, it is interesting to note that some teachers are even influenced by their pupils' errors in the course of long teaching.

5) Fossilization: Some errors, especially errors in pronunciation, persist for long periods and become quite difficult to get rid of.

6) Avoidance: Some syntactic structures are difficult to produce by some learners. Consequently, these learners avoid these structures and use instead simpler structures.

7) Inadequate learning: it is mainly caused by ignorance of rule restrictions or under differentiation and incomplete learning. An example is omission of the third person singular s as in: He want.

8) False concepts hypothesized: Many learners' errors can be attributed to wrong hypotheses formed by these learners about the target language. [19] (Touchie 1986, pp.78-79).

\section{METHODOLOGY}

This section presents the research methodology used in this study; more importantly, the sample and the population, the data collection instruments and procedures will be discussed.

The present research utilized purposive sampling method. The sample was deliberately chosen to extract the most relevant information. The reason of selecting the purposive method is that the researcher is well aware of the participants and their level of English language proficiency. According to [20] Denscombe (2014), purposive sampling method is used when the researcher already knows about the specific people and believe that these people can help produce the most valuable data.

The sample of the present study included seventy students who are currently following HNDE course at ATI Anuradhapura. The sample was chosen to represent whole program: 35 from the first year class and 35 from the second year class. 
The participants of this study are adult learners and their age is between 20 and 25 years. All of them are from Anuradhapura district of North Central Province in Sri Lanka. Their proficiency levels are low, ranging between pre intermediate and below that. The social backgrounds of the learners vary. Majority of the learners come from middle class farming families. However, there are a few learners whose family background differs from the majority learners. They belong to families that can afford to provide their children with facilities to learn English in a better way.

Since the present research was essentially based on students' writing ability, the best instrument of data collection was to ask the participants to write essays. The main aim of the study was to review the HNDE 1st and 2nd year students' writing productions and compare and contrast the errors that they make in their writings by placing emphasis on English grammar.

These participants were chosen to represent whole HNDE program: half from the first year group and half from the second year group. The researcher randomly selected thirty five from each group and then they were asked to write an assay. She did not restrict them to any word limit. It is because she wanted to create a stress-free environment so that they are motivated to express their own ideas using their own writing styles. Moreover, the researcher was well aware of the fact that their English language competency level was not higher enough to write academic essays. Therefore, the essay topics were personalized. Thus, the two essay topics provided were 'my favorite person' and 'the unforgettable day'. They were asked to choose one topic of their interest and write an essay on it.

\section{RESULTS AND DISCUSSION}

This section presents the results of the current study and the analysis of these results. The results are presented in two main divisions: HNDE first year student results and HNDE second year student results. These two categories will be merged in each discussion section

\section{Frequency of errors}

After identifying grammatical errors, they were classified into four main processes described above. Total errors that the first year participants made were 610 . The highest number of errors was found in the Omission category which was 37\%, and the lowest number of errors was in relation to Permutation category which was $7 \%$. The second largest area of making errors was substitution and the percentage was 33\%. Third highest number of errors was in the Addition category which was $23 \%$.

Table 1: Frequency of errors of HNDE $1^{\text {st }}$ year students' errors

\begin{tabular}{|c|c|c|c|c|c|}
\hline \multirow{2}{*}{} & \multicolumn{5}{|c|}{ HNDE 1 ${ }^{\text {st }}$ year } \\
\cline { 2 - 6 } & $\begin{array}{c}\text { Ad } \\
\text { diti } \\
\text { on }\end{array}$ & $\begin{array}{c}\text { Om } \\
\text { issi } \\
\text { on }\end{array}$ & $\begin{array}{c}\text { Sub } \\
\text { stit } \\
\text { utio } \\
\text { n }\end{array}$ & $\begin{array}{c}\text { Per } \\
\text { mut } \\
\text { atio } \\
\text { n }\end{array}$ & $\begin{array}{c}\text { TT } \\
\text { L }\end{array}$ \\
\hline Number of errors & 142 & 228 & 201 & 16 & 490 \\
\hline Percentages & 23 & 37 & 33 & $3 \%$ & $\begin{array}{c}100 \\
\%\end{array}$ \\
\hline
\end{tabular}

Total number of errors made by $2^{\text {nd }}$ year students was 490 . The highest number of errors was found in the omission category which was $41 \%$, and the lowest number of errors was in relation to permutation category which was $3 \%$. The second largest area of making errors was substitution and the percentage was $36 \%$. Third highest number of errors was in the Addition category which was $20 \%$. Table 2 .

Table 2: Frequency of errors of HNDE $2^{\text {nd }}$ year students' errors

\begin{tabular}{|c|c|c|c|c|c|}
\hline \multirow{2}{*}{} & \multicolumn{5}{|c|}{ HNDE 2nd year } \\
\cline { 2 - 6 } & $\begin{array}{c}\text { Ad } \\
\text { diti } \\
\text { on }\end{array}$ & $\begin{array}{c}\text { Om } \\
\text { issi } \\
\text { on }\end{array}$ & $\begin{array}{c}\text { Sub } \\
\text { stit } \\
\text { utio } \\
\text { n }\end{array}$ & $\begin{array}{c}\text { Per } \\
\text { mut } \\
\text { atio } \\
\text { n }\end{array}$ & $\begin{array}{c}\text { TT } \\
\text { L }\end{array}$ \\
\hline Number of errors & 96 & 200 & 178 & 39 & 610 \\
\hline Percentages & 20 & $\begin{array}{c}41 \\
\%\end{array}$ & $\begin{array}{c}36 \\
\%\end{array}$ & $7 \%$ & $\begin{array}{c}100 \\
\%\end{array}$ \\
\hline
\end{tabular}

\section{Analysis: addition}

In relation to the process of addition, it is apparent that there is a significant improvement of the HNDE $2^{\text {nd }}$ year students. It was clear from the findings that the number of areas that the $2^{\text {nd }}$ year participants made mistakes were fewer than the $1^{\text {st }}$ year participants. This clearly reveals that the second year participants have reached a remarkable level of improvement in terms of the process of addition.

\section{a). He was very clever to cooks \\ b). She tries to protects me}

In the present study, the example sentences (a) and (b) show how the learners use the third person singular marker, the morpheme "s" in prepositional phrases " to cooks" and "to protects". These errors are due to either overgeneralization of the rules or insufficient knowledge about the rules.

Another common error made by both HNDE $1^{\text {st }}$ year and $2^{\text {nd }}$ year students is the addition of the verb 'be'. 
c). So, I am try to be a good English teacher

d). I was did naughty work

e). She is very like children

In each of the above sentences, the participants use the verb 'be' inappropriately. The cause of this error can be hypothesizing false concepts. These errors can be attributed to wrong hypotheses formed by these learners about the tense markers in English language. For instance, they seem to think that is is the marker of the present tense, and therefore they add 'is' inappropriately within the sentence

According to the present researcher's observations, addition of preposition 'to' occurs often in L2 learners' writing in Sri Lanka. It is due to L1 transfer.

f). He never punishes to me.

g). We attended to my uncle's 7 days chanting.

In these sentences, the participants used preposition 'to' inappropriately. They, in this instance, misinterpret one of the functions of preposition 'to', which is the preposition 'to' is used for showing who receives something or who experiences an action. In fact, any of the above sentences do not require the preposition 'to' immediately after the main verb of the sentence. Thus, they make this error because it sounds correct for them in comparison with their first language. These learners seem to think in L1 which is Sinhala and produce a translation in English. Direct translation, thus, was the main source of writing errors. This, in many instances, prevented learners from using preposition correctly; especially, they were confused with the preposition "to".

\section{Omission}

Even though there is not a huge gap between the numbers of errors that both groups made, the number of main areas of making errors have been reduced in the second year group.

In comparing the HNDE $1^{\text {st }}$ and $2^{\text {nd }}$ year students' errors, it is evident that the HNDE $2^{\text {nd }}$ year students have improved their grammar knowledge to a certain extent. However, it is important to note that the areas that these learners are still making errors are basic based on the fact that they are expected to be English language teachers at the end of their second year.

[21]Chen (2000) points out that Taiwanese EFL students find it difficult to learn articles in English since there is not an equivalent syntactical device to the English article system. In the case of present participants, indefinite article is abundantly used in their L1, and therefore present learners lack knowledge regarding English indefinite article ' $a$ ' since they have not internalized the relevant grammar rules.

However, L1 of the present learners does not include the definite article. Therefore, the omission of definite article in their writings can be caused by their L1 influence. h) Mother' is most beautiful word in the world

i) He is best and great person in my life

Thus, the errors found in the above example sentences are caused by L1 influence. For example, the meaning given by the superlative adjective "best" along with the definite article "the", make sense to a Sri Lankan

It is not always L1 interference that causes errors. Intralingual and development errors can also have a great impact on the present learner errors. For example, omission of the verb 'be' and omission of the third person singular marker ' $\mathrm{s}$ ' in sentences are caused by the inadequate learning. In other words, these learners are ignorant of rule restrictions or their learning is incomplete. These are new rules that the learners are supposed to master in L2 learning and equivalent rules for them cannot be found in Sinhala, the first language of the present learners.

Omission of possessive marker, the morpheme ' $s$ ' is another significant error made by the present participants. This error is not caused by the interference of L1 since Sinhala language includes a possessive marker just as English language does. In terms of the learners who make this error, it is more closely due to inadequate learning. This clearly shows the learners' carelessness in learning and exercising what they have learnt. This also indicates their level of mastery of the L2.

Moreover, omission of the main verb and omission of the subject of a sentence are serious grammatical errors made by the HNDE $1^{\text {st }}$ year learners. They are serious in that they directly damage the meaning that the sentence is supposed to convey to the reader. Furthermore, the subject of a sentence is the doer of the main action indicated by the main verb. These two elements can be considered the spine of a sentence. Omitting either the verb or the subject, therefore, can be considered a serious error that any writer can ever make. It is an obvious fact that this type of errors are not caused by the L1 interference, because both in Sinhala and English the basic sentence structure includes Subject and Verb. For example, the structure of a simple sentence in Sinhala language is Subject + Object + Verb (SOV), and the simple sentence structure of English is Subject+ Verb+ Object. Thus, it is clear that both languages share similar elements of a sentence and therefore omission of either the Subject or the Verb is not caused by L1 influence. However, it is obvious that these learners make these errors due to inadequate learning. They have not gained the required mastery of the language, and therefore they make these errors.

\section{Substitution}

In comparing the HNDE $1^{\text {st }}$ and $2^{\text {nd }}$ year participants' errors in relation to the process of substitution, it is obvious that the HNDE $2^{\text {nd }}$ year participants' grammar knowledge is a little higher than the $1^{\text {st }}$ year participants. However, it is important to note that the areas that these learners are still making errors are important ones to have been improved by students from HNDE final year class. 
Substitution of a word from a different word class is a common error type made by both groups. They seem to go beyond what they know about L2 and as a result they write grammatically incorrect sentences.

j) I never unforgettable that day in my life.

k) She can cook very taste

1) He always think about my happy.

Substitution of a wrong preposition is also a significant error type made by the present learners.

o). He spends a lot to me

p). Sometimes he tells story of me

This kind of errors can be described in terms of interlingual errors. As a matter of fact, prepositions do not exist in the L1 of these participants, but there are other ways in Sinhala language that help convey the meanings indicated by English prepositions. However, for example, the meanings produced by 'in' as a preposition of place and 'on' as a preposition of time is confusing to Sinhalese learners since Sinhala language includes only a single letter for both of these functions.

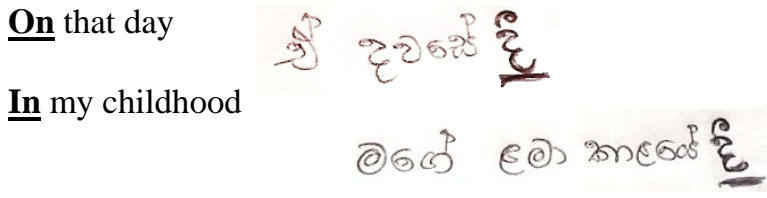

In the above translation, it is clearly shown that for both prepositions 'in' and 'on', bold underlined Sinhala letter is used. Therefore, most of the errors in relation to prepositions are caused by L1 interference.

Another important type found in this study is the substitution of a non-existent word in which the participants seemed to create new words using the roots that they know. Even though this type of error is directly related to English vocabulary, these errors also have a great impact on English grammar since these words cause inaccuracy of the sentences.

\section{q). She feeds us very goodly}

r). My mother is strenthful, curregerble, honest and good mother.

s). If someone better people habitted to follow those one

The source of this particular error is obvious in that these learners try to extend the application of one form in one context to other contexts where it should not apply. Therefore, overgeneralization has caused these errors.

\section{CONCLUSION}

According the data collected and the discussions carried, it is clear that both $1^{\text {st }}$ year and $2^{\text {nd }}$ year learners make similar errors in their L2 writing. The common areas of making errors were found to be articles, prepositions, pronouns and be verbs. Using third person singular marker 's' was also a significant error made by these learners.
Even though most of the errors made by $1^{\text {st }}$ year and $2^{\text {nd }}$ year participants were the same, in each process, $2^{\text {nd }}$ year participants showed an improvement, but this is insignificant in terms of the expectations of the HNDE course. For example, second year participants substituted incorrect pronouns for correct ones in sentences. Usually, in the first year first semester, all the word classes are taught, but these learners are still making errors in relation to basic English grammar. Therefore, it cannot be concluded that there is a huge difference in the mistakes that these two groups of participants made.

In terms of the processes, the results were consistent in both $1^{\text {st }}$ year and $2^{\text {nd }}$ year participants. In both groups, the process of omission marked the highest number of errors; the second highest number of errors was recorded by the process of substitution; the third highest number of errors was found in the process of addition and the lowest number of errors was recorded by the process of permutation. This suggests the similarity between first year and second year participants in terms of the types of errors.

There were significant grammar errors in these participants' essays. In fact, majority of them showed insufficient knowledge regarding the preposition 'to'. In their essays, they overused this preposition, which hindered the smooth flow of their essays. Thus, the misuse of the preposition 'to' was predominant among the errors that the participants of this study had made. It was found out that it is mainly because they tried to translate a meaning that they constructed in their L1 into L2.

\section{REFERENCES}

[1] Jobeen, Agsa and Kazemian, Bahram and Shahbaz, Muhammad, The Role of Error Analysis in Teaching and Learning of Second and Foreign Language (September 13, 2015). Education and Linguistics Research, 1(2), 52-62. DOI:10.5296/elr.v1i1.8189, Available at SSRN: https://ssrn.com/abstract=2659714W.-K. Chen, Linear Networks and Systems (Book style). Belmont, CA: Wadsworth, 1993, pp. 123-135.

[2] Corder, S.P. (1976). The Significance of Learner"es Errors. 1RAL, 5, 161 170 .

[3] Selinker, L. 1972. Interlanguage. IRAL. 10, 209-231.

[4] Fisiak, J. 1981. Contrastive Linguistic and the Language Teacher. Oxford: Oxford Pergamon Press

[5] Al-khresheh, M.H., 2015. A Review Study of Interlanguage Theory. International Journal of Applied Linguistics and English Literature, 4(3), pp.123-131

[6] James, C. (1998). Errors in Language Learning and Use. London: Longman.

[7] Comrie, B. (1990). Second language acquisition and language universals research. Studies in Second Language Acquisition, 12, 209-218.

[8] Major, R. and Faudree, M., 1996. Markedness universals and acquisition of voicing contrasts by Korean speakers of English. Studies in Second Language Acquisition, 18, 69-90.

[9] Corder, S. P. (1967).The significance of learners' errors. IRAL, 5, 161-170.

[10] Khansir, A.A., 2012. Error analysis and second language acquisition. Theory and practice in language studies, 2(5), p.1027.

[11] Hassan, M., Sawalmeh, M.Z., Arabia, S., \& Sawalmeh, M. (2013). Error Analysis of Written English Essays: The case of Students of the Preparatory Year Program in Saudi Arabia.

[12] Corder, S. P. (1974). Error Analysis: Perspectives on second language acquisition. London: Longman.

[13] Bhela, B., 1999. Native language interference in learning a second language: Exploratory case studies of native language interference with target language usage. International Education Journal, 1(1), pp.22-31. 
[14] Ellis, R., 1997. Second Language Acquisition. Oxford: Oxford University Press.

[15] Mahmoud, A., 2000. Modern standard Arabic vs. non-standard Arabic: Where do Arab students transfer from? Language, Culture and Curriculum, 13, 126-136.

[16] Karim, K. and Nassaji, H., 2013. First language transfer in second language writing: An examination of current research. Iranian Journal of Language Teaching Research, 1(1), pp.117-134.

[17] Pratiwi, A.P., 2016. Interlingual and intralingual errors in writing narrative text made by junior high school and senior high school students. Jurnal Penelitian Humaniora, 16(2), pp.1-11.

[18] Schachter, J., \& Celce-Murcia, M.1977. Some reservations concerning error analysis. TESOL Quarterly, 11, 441-51. http://dx.doi.org/10.2307/3585740

[19] Touchie, H.Y., 1986. Second language learning errors their types, causes, and treatment. JALT journal, 8(1), pp.75-80.
[20] Denscombe, M., 2014. The good research guide: for small-scale social research projects. McGraw-Hill Education (UK).

[21] Chen, H. C., 2000. Error Analysis of some features of English article usage. Journal of Wu-Feng Applied Linguistics, 8, 282-296.

\section{AUTHOR}

First Author - Jasmine Jayasekara, Master of Arts, Sri Lanka Institute of Advanced Technological Education (SLIATE), jasmine@ sliate.ac.lk. 